patients with the first biologic indicated. Loss of efficacy was the most frecuent cause $(62 \%)$ of therapy change. Currently golimumab and etanercept are the most commonly used, prescribed in 5 (33\%) and 4 (26\%) patients respectively.

Abstract AB0870 - Table 1. Baseline characteristics of the cohort (first recorded visit) $(\mathrm{N}=78)$

\begin{tabular}{|c|c|c|c|}
\hline Type of SpA N(\%) & $\begin{array}{l}\text { AS } 78 \\
(100 \%)\end{array}$ & $\begin{array}{l}\text { Inflammatory } \\
\text { back pain (\%) }\end{array}$ & 75 (96.2\%) \\
\hline $\begin{array}{l}\text { HLA-B27 + } \\
\mathrm{N}(\%)\end{array}$ & $70(89.6 \%)$ & $\begin{array}{c}\text { Sacroiliitis (NY } \\
\text { criteria) } \\
N(\%)\end{array}$ & $\begin{array}{c}\text { Mild: } 8 \\
(10.3 \%) \\
\text { Moderate: } 25 \\
(32.1 \%) \\
\text { Severe: } 45 \\
(57.7 \%)\end{array}$ \\
\hline $\begin{array}{l}\text { Sex } \\
N(\%)\end{array}$ & $\begin{array}{c}\text { Male } 67 \\
(85.9 \%) \\
\text { Female } 11 \\
(14.1 \%)\end{array}$ & $\begin{array}{c}\text { CRP } \\
\text { Mean(DS) mg/dL }\end{array}$ & $12.2(13.4)$ \\
\hline $\begin{array}{l}\text { Age Moment of registration Start of } \\
\text { symptoms Moment of the diagnosis } \\
\text { Mean (DS) years }\end{array}$ & $\begin{array}{c}48(9.7) 25.9 \\
(10.2) 35.01 \\
(10.3)\end{array}$ & $\begin{array}{c}\text { Extra-axial } \\
\text { manifestations } \\
\text { Uveítis } \\
\text { Lower limbs } \\
\text { peripheral arthritis } \\
\text { Enthesitis } \\
\text { Dactilitis } \mathrm{N}(\%)\end{array}$ & $\begin{array}{c}1924.7 \%) 19 \\
(24.4 \%) 34 \\
(43.6 \%) \\
6(7.7 \%)\end{array}$ \\
\hline $\begin{array}{l}\text { Time of evolution } \\
\text { Diagnosis-inclusion in the registry }\end{array}$ & $13(9.2)$ & $\begin{array}{l}\text { Hip prosthesis } \\
\mathrm{N}(\%)\end{array}$ & $5(6 \%)$ \\
\hline
\end{tabular}

Conclusions: The results obtained suggest that the follow-up of a cohort of patients with spondyloarthritis in a specialised monographic medical centre allows a control of the symptoms, with a low recurrence of extra-axial manifestations. We can conclude from this study that most patients with spondyloarthritis $(75 \%)$ could have good control of their disease with NSAIDs in the long term.

Disclosure of Interest: None declared

DOI: 10.1136/annrheumdis-2018-eular.4744

\section{AB0871 1 PREDICTIVE VALUES OF INFLAMMATORY LOW BACK PAIN, POSITIVE HLA B 27 ANTIGEN, INCREASED C REACTIVE PROTEIN, POSTIVE MAGNETIC RESONANCE AND OTHER FEATURES IN AXIAL SPONDILOARTHRITIS (SPA). A PROSPECTIVE 2 YEARS FOLLOW UP}

L.Y. Komsalova ${ }^{1}$, A. Valdivia ${ }^{2}$, P.M. Salinas ${ }^{3} .{ }^{1}$ Rheumattology; ${ }^{2}$ Epidemiology and preventive medicine; ${ }^{3}$ Radiology department, Hospital Marina Salud, Denia, Spain

Background: Diagnosis of Spondyloarthritis remains challenging in the daily practise. Inflammatory back pain might be a good tool for early diagnosis.

Objectives: To analyse sensitivity, specificity and predictive values of inflammatory back pain (IBP), positive HLA B27 antigen, increased C-reactive protein (CRP), positive sacroiliac joints (SI) magnetic resonance (MRI) imaging, additional features $(A F)$ such as peripheral arthritis, dactylitis, psoriasis, uveitis, inflammatory bowel disease (IBD) and familiar history $(\mathrm{FH})$ and assesse probabilities to develop SPA

Methods: We prospectively collected and follow up 82 patients referred to our department with suspicion of SPA from September 2014 to December 2016. Data such as IBP, HLA B27, additional features, familiar history of SPA, increased CRP, sacroiliac $x$-Rays and sacroiliac MRI imaging was performed for each patient. Each MRI image was separately and independently evaluated by rheumatologist and radiologist.

Results: The average age in our study was 39.8 years with male/female ratio 0.4 / 1. $37(45.1 \%)$ patients were diagnosed with axial SPA. Radiographic sacroiliitis had only $5(6.1 \%)$ patients. AF had $21(25.6 \%)$ patients. IBP was found in 36 (43.9\%) patients, positive HLA B 27 antigen in 24 (29.3\%) and increased CRP in $22(26.8 \%)$. Sacroiliac joints (SI) MRI images were assessed as clearly positive if patients had more than 2 highly specific for SPA bone marrow oedema (BME) lesions, at least 3 fatty lesions and more than 1 erosion, positive MRI image if patients had at least 2 highly specific BME lesions, and clearly negative MRI images if patients had not got any of those features. We found $83.78 \%$ sensitivity and $88.89 \%$ specificity for IBP, $37.84 \%$ sensitivity and $80.95 \%$ specificity for positive HLA B27 antigen, $43.24 \%$ sensitivity and $88.1 \%$ specificity for increased CRP. AF such as such as peripheral arthritis, dactylitis, psoriasis, uveitis and IBD, evaluated together reached sensitivity $37.84 \%$ and specificity $84.44 \%$. Positive $\mathrm{FH}$ only contributed to the diagnosis with $13.51 \%$ sensitivity, but showed higher specificity (84.44\%). Sensitivity for positive SIJ MRI imaging were poor (51.35\%) but reached excellent specificity $(100 \%)$. Predictive values in our study were as follows: $86.11 \%$ predictive positive values (PPV) and $86.96 \%$ predictive negative value (PNV) for IBP, 63.64\% PPV and 59.65\% PNV for HLA B27, 76.19\% PPV and $63.79 \%$ PNV for increased CRP, 66.67\% PPV and $62.30 \%$ PNV for AF.
Positive FH contributed to the diagnosis with 66.67\% PPV and 62.30\% PNV. Positive MRI reached $100 \%$ PPV and showed high PNV -71.43. Multivariate analysis displayed $81.8 \%$ likelihood to be diagnosed for SPA if only IBP without AF at the onset of the diagnosis and $94.8 \%$ if both IBP and AF were presented.

Conclusions: At the onset, IBP may be a good indicator for SPA with high sensitivity and acceptable specificity. Additional feature such as peripheral arthritis, dactylitis, psoriasis, uveitis and IBD might increase the possibility of SPA. HLA B27 antigen. increased CRP and FH brings low sensitivity for SPA nevertheless, specificity is better. Positive SI MRI imaging is highly specific but lacks sensibility. Normal SI radiography at the onset does not rule out diagnosis of SPA.

Disclosure of Interest: None declared

DOI: 10.1136/annrheumdis-2018-eular.1345

\section{AB0872 QUANTIFERON TB GOLD TEST IN DIAGNOSIS OF LATENT TUBERCULOSIS INFECTION AMONG A MOROCCAN POPULATION WITH SPONDYLOARTHRITIS}

J. Eddarami, L. Ichchou. Department of Rheumatology, Mohamed VI University Hospital, Mohammed I University, Oujda, Morocco

Background: Patients treated with anti-tumour necrosis factor-alpha (anti-TNF$\alpha)$ are at increased risk for latent tuberculosis reactivation. However, the best method for latent tuberculosis infection (LTBI) detection before initiation of antiTNF therapy remains to be determined.

Objectives: The aim of this study is to investigate the role of QuantiFERON-TB Gold test as one of the interferon-gamma release assays (IGRAs) in detecting LTBI before initiation of biotherapy in a population of Moroccan patients suffering from spondyloarthritis (SpA).

Methods: We have conducted a cross-sectional study over two months in our department of rheumatology. All SpA patients fulfilled ASAS 2009 criteria.

Tuberculin skin test (TST), Quantiferon-TB Gold in Tube (QFT-GIT) assay and chest radiographs were performed before starting anti-TNF-alpha. Computed tomography was performed in patients with abnormal chest radiographs.

Results: We included ninety tow patients with SpA. Among them, 35 (38\%) received anti-TNF- $\alpha$ therapy. A history of tuberculosis disease was noted in 6 patients $(6.6 \%$ ) (3 Pulmonary TB and 3 extrapulmonary TB). Two patients $(2.2 \%)$ had contagious tuberculosis. The positive QFT-GIT rate was $15.2 \%(14 / 35)$. The TST was negative in $16.3 \%$ of cases (15/35). The results of QFT-GIT and TST performed in the same patients were discordant in 5 cases $(5.4 \%)$. Sputum smears were negative. Chest CT performed in 29 patients had shown bronchiectasis in 3 cases (3.7\%), interstitial syndrome in 2 cases $(2.5 \%)$ and was normal in 24 cases $(29.6 \%)$

The chemoprophylaxis was prescribed in 14 persons with a positive QFT-GIT. It was based on Isoniazid (INH) alone in 12 cases (13\%), a triple therapy $(\mathrm{RHZ})$ in one case $(1.1 \%)$ and a quadritherapy (RHZE) in another case with active tuberculosis. The duration of chemoprophylaxis varied between 6 and 9 months in the case of monotherapy, 2 months in the case of triple therapy because of biologic hepatotoxicity and 6 months in the case of quadritherapy because of active TB occurring during anti-TNF alpha therapy. The delay in initiating biotherapy varied between 1 and 6 months. At the time of blood sampling for QFT-GIT, patients were receiving: steroids in one case (1.1\%), Methotrexate (MTX) and steroids in 3 cases (3.3\%), Sulfasalazine (SZP) in 3 cases (3.3\%), MTX in 4 cases $(4.3 \%)$ and MTX and SZP in 2 cases (2.2\%)

Conclusions: QTB-G may be a more sensitive screening tool for LTBI before initiating anti-TNF therapy in immunocompromised patients, especially in a TB endemic country.

\section{REFERENCES}

[1] Ramos S, et al. Tuberculosis screening in patients receiving biological therapy. Acta Reumatol Port 2015;40:234-40.

[2] Kim HC, et al. Diagnosis of latent tuberculosis infection before initiation of anti-tumor necrosis factor therapy using both tuberculin skin test and quantiFERON-TB Gold in Tube assay. Scand J Infect Dis 2014;46:763-9.

[3] Saidenberg-kermanac'h N, et al. Screening for latent tuberculosis in antiTNF- candidate Patients in a high tuberculosis incidence setting. Int Tuberc Lung Dis 2012;16:1307-14.

[4] Redelman-Sidi G, et al. IFN- $\gamma$ Release assays in the diagnosis of latent tuberculosis infection among immunocompromised adults. AJRCCM 2013;188:422-31.

Disclosure of Interest: None declared

DOI: 10.1136/annrheumdis-2018-eular.6777 